\title{
Implementing Comparative Method in Education With the case of Leaf Lettuce Irradiation Modes
}

\section{Implementación del método comparativo en educación con el caso de los modos de irradiación de lechuga de hoja}

\author{
Olga E. Zheleznikova*(i) \\ N.P.Ogarev National Research Mordovia State University, Mordovia, Rusia \\ ORCID: https://orcid.org/0000-0002-1560-4144 \\ Aleksandr B. Myshonkov \\ N.P.Ogarev National Research Mordovia State University, Mordovia, Rusia \\ ORCID: https://orcid.org/0000-0001-9897-1080
}

Recibido 03-12-19 Revisado 15-01-20 Aprobado 10-03-20 En línea 14-03-20

Correspondencia

Email: O.E.Zheleznikova@gmail.com

\section{Citar como:}

Zheleznikova, O. E., \& Myshonkov, A. B. (2020). Implementing Comparative Method in Education With the case of Leaf Lettuce Irradiation Modes. Propósitos y Representaciones, 8(3). doi: http://dx.doi.org/10.20511/pyr2020.v8n3.478

\footnotetext{
(c) Universidad San Ignacio de Loyola, Vicerrectorado de Investigación, 2020. (c) EY-No-ND Este artículo se distribuye bajo licencia CCBY-NC-ND 4.0 Internacional (http://creativecommons.org/licenses/by-nc$\mathrm{nd} / 4.0 /)$.
} 


\section{Summary}

The article presents the results of four series of experimental studies of irradiation efficiency of Moskovskii Parnikovyi leaf lettuce with general and special-purpose LED lamps (phyto-lamps) under various irradiation modes. The studies were conducted with an automated experimental irradiation device. The influence of the spectral compositions of LED radiation on the growth and development of Moskovskii Parnikovyi leaf lettuce is estimated. The studies have shown that LED phyto lamps are more effective in terms of productivity of Moskovskii Parnikovyi leaf lettuce compared to general-purpose LED lamps with equal electrical power consumption.

Keywords: Leaf Lettuce; LED Lamp; Automated Irradiation Unit; Irradiation Mode; Radiation Spectrum

\section{Resumen}

El artículo presenta los resultados de cuatro series de estudios experimentales sobre la eficiencia de irradiación de la lechuga de hoja Moskovskii Parnikovyi con lámparas LED generales y especiales (fito-lámparas) bajo varios modos de irradiación. Los estudios se realizaron con un dispositivo de irradiación experimental automatizado. Se estima la influencia de las composiciones espectrales de la radiación LED en el crecimiento y desarrollo de la lechuga de hoja Moskovskii Parnikovyi. Los estudios han demostrado que las fito lámparas LED son más efectivas en términos de productividad de la lechuga Moskovskii Parnikovyi en comparación con las lámparas LED de uso general con el mismo consumo de energía eléctrica.

Palabras clave: Lechuga de hoja; Lámpara LED; Unidad de irradiación automatizada; Modo de irradiación; Espectro de radiación.

\section{Introduction}

The photosynthetic effectiveness depends on many factors, mainly on lighting conditions (irradiation), ambient temperature, carbon dioxide concentration, moisture and soil mineral composition. All these factors together affect the overall productivity of plants. In this case, optical radiation has a photosynthetic and thermal effect on plants. Plants partially use the radiation energy absorbed for photosynthesis, and another part for heating and water evaporation (transpiration). Under natural climatic conditions, approximately $2 \%$ of the energy incident on plants is used for photosynthesis (Mokronosov et al., 2006), that is, the main energy expenditures for growing plants are associated with the creation of conditions for photosynthesis.

Currently, industrial crop production in greenhouses is one of the most dynamically developing sectors of agroindustry. Salad-green crops account for $10 \%$ in the structure of greenhouse production using light culture (Pchelin \& Makarova, 2018). Consumer demand for lettuce (Latuca sativa L.) during the off-season is quite high. In this regard, research has been conducted (Kurshev et al., 2019) aimed at increasing the production of lettuce culture.

It is well known that the spectral composition of radiation has a decisive role in the growth, development, and productivity of lettuce plants; thus, growing in protected ground requires optical radiation sources (ORS), the radiation spectrum of which would not only be consistent with the region of maximum photosynthetic action, but had a plant-friendly regulatory spectral response. Thus, exposure to only red light leads to elongation of plants and a decrease in lettuce biomass (Hoenece et al., 1992). Salad grown under red light with the addition of blue has 
a higher dry weight (Bula et al., 1991). Adding green radiation to red and blue contributes to the growth of lettuce (Kim et al., 2004).

Radical changes in greenhouse lighting occur against the background of the rapid development of LED light sources (LEDs) (Brian et al., 2018; Tewolde et al., 2018). Having reached and surpassing the level of sodium phytoradiators in energy efficiency, LED phytoradiators also surpass them in optimizing the spectral characteristics considering the specific features of individual crops and growing tasks (Prikupets, 2017). The study of the possibility of increasing the efficiency of irradiation facilities through the use of automated lighting control systems is also relevant.

The objective of the study is to compare the irradiation modes of Moskovskii Parnikovyi leaf lettuce using automated control systems.

\section{Main Part}

To conduct laboratory studies of the effectiveness of the irradiation modes of Moskovskii Parnikovyi leaf lettuce, an experimental irradiation device was developed consisting of three isolated boxes $25 \times 25 \times 35 \mathrm{~cm}$, painted white with a reflection coefficient $\rho=0.8$. As the ORS in the boxes, LED lamps (LED) with an automated control system were used. The main elements of the automated control system are microcontroller, relay, real-time clock, and light sensor. The microcontroller is a key element of the control system that implements various control algorithms. In the experiments, the microcontroller managed ON/OFF function of LEDs through an electromagnetic relay based on data from the real-time clock (turning on and off the ORS at a certain time) and on the basis of data from the light sensor (turning on and off the ORS when a certain level of natural exposure was reached). The controller also made it possible to record the intensity of natural light (Ulianova \& Myshonkov, 2017).

Three types of LEDs were used to irradiate Moskovskii Parnikovyi leaf lettuce plants (spectra are shown in Figures 1-3):

- LEDs with a correlated color temperature $\left(\mathrm{T}_{\text {col }}\right) 4000 \mathrm{~K}$;

- LEDs with $\mathrm{T}_{\mathrm{col}}=6500 \mathrm{~K}$;

- phyto-LEDs.

The investigated LEDs were professionally monitored at the Center for Lighting Engineering Metrology, FSBEI HE, N.P. Ogarev Moscow State University.

Lettuce was planted on February 26, 2019. Watering was carried out every other day, the ambient temperature was maintained in the range of $19-22{ }^{\circ} \mathrm{C}$.

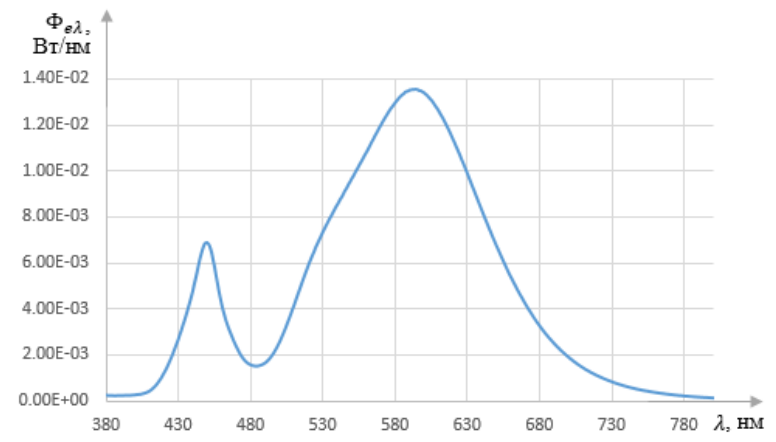

Figure 1: LED radiation spectrum with Tcol $=4000 \mathrm{~K}$ 


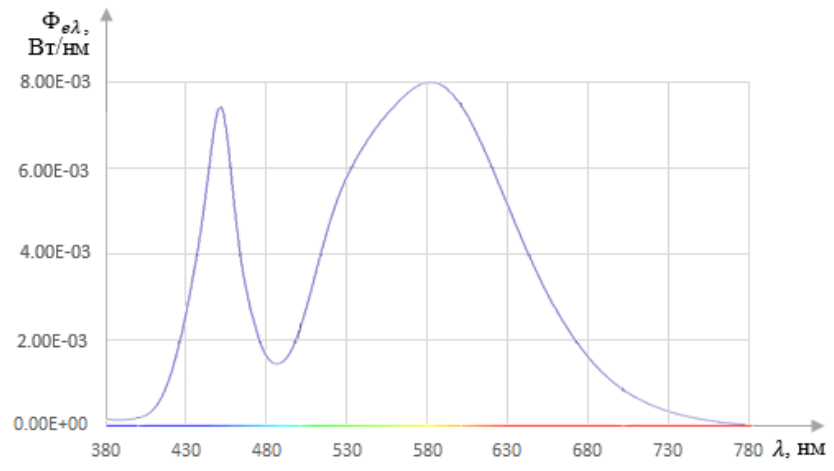

Figure 2: LED radiation spectrum with Tcol $=6500 \mathrm{~K}$

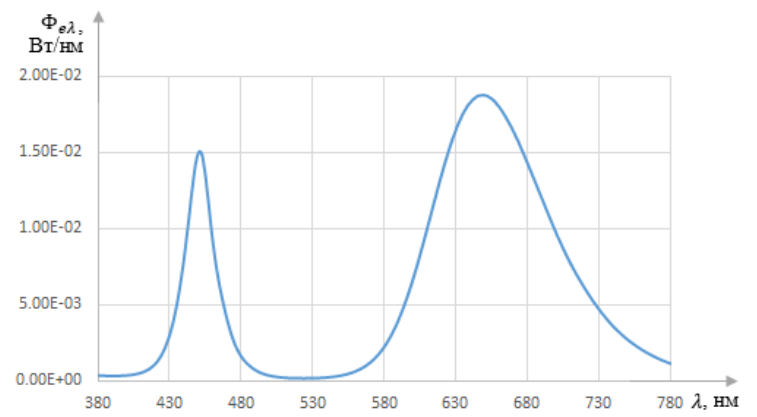

Figure 3: Phyto-LED radiation spectrum

Ready-made soil "BIOgrunt EkoFlora Universalnyi" was used as a substrate, consisting of a mixture of peat of various degrees of decomposition (70\%), sapropel (10\%), river sand (4\%), vermiculite/agroperlite $(5 \%)$, and fertilizer "FlorGumat" $(5 \%)$, dolomitic lime flour (1\%). The soil is saturated with nutrients: mineral nitrogen - $300 \mathrm{mg} / \mathrm{l}$; mobile phosphorus - $300 \mathrm{mg} / \mathrm{l}$; mobile potassium - $350 \mathrm{mg} / \mathrm{l}$; the presence of trace elements - boron, molybdenum, manganese, zinc, copper, cobalt, iron.

Artificial salad lighting began on the third day after the appearance of the first shoots. Phenological observations were carried out to monitor the dynamics of the following indicators: the height of the rosette, the width and length of the sheet, the number of leaves in the rosette.

Four series of experimental studies were conducted:

- study of the effect of natural light on the mode of additional treatment of leaf lettuce plants;

- study of the influence of the spectral composition of LED radiation on the efficiency of irradiation under natural light;

- study of the influence of the spectral composition of LED radiation on the efficiency of irradiation without natural light; light.

- study of the effect of the periodic exposure on its effectiveness in the absence of natural

Study of the effect of natural light on the plant supplementary lighting mode. The first series of experiments used three modes:

- LED supplementary lighting against the real-time clock excluding natural light during the day (in the morning and evening hours: 6.00 - 8.00 and 17.00 - 20.30); 
- LED supplementary lighting against the real-time clock including natural light during the day (LEDs were turned on at 6:00, turned off at 20:30, and according to the photosensor signals, the SDLs were turned off at sufficient natural light);

- without supplementary lighting (control).

During the laboratory experiments, the levels of illumination, the duration of the on and off artificial lighting (illumination) of lettuce plants were recorded. The duration of artificial illumination in the first series of experiments was 206 hours, in the second - 385 hours.

Lettuce growth in the series of experiments with and without supplementary proceeded evenly throughout the period, and in the series with lighting against clock (only in the morning and evening hours), lettuce retarded from the 17th to 25 th day of the experiment, which can be explained by the insufficient levels of illumination (irradiation) during the day when artificial illumination was turned off.

The biometric indicators of Moskovskii Parnikovyi leaf lettuce plants irradiated with LED including natural lighting are shown in Figure 4.

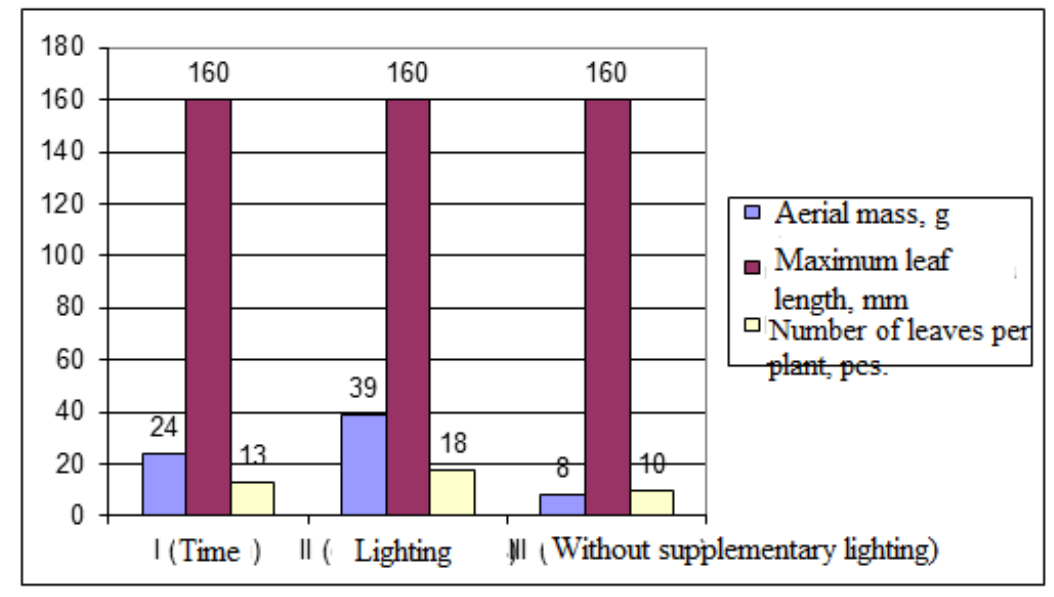

Figure 4. Biometric indicators of Moskovskii Parnikovyi leaf lettuce plants irradiated with LED including natural lighting.

The results of the first series of experiments showed that insufficient levels of illumination in the winter-spring period led to a significant decrease in the rate of development of leaf lettuce. In the case of growth without additional irradiation, its leaves and root system developed much weaker compared to the variants with artificial illumination.

Study of the influence of the spectral composition of LED radiation on the leaf lettuce irradiation efficiency under natural light. In the second series of laboratory experiments, the same 3 modes were studied as in the first.

The results of the experimental studies are shown in Figure 5. The variant with illumination of phyto-LEDs had larger leaves and their number was slightly higher than in the variant illuminated with of general-purpose LEDs. The use of phyto-LEDs for artificial illumination of leaf lettuce increases the productivity of lettuce by $15 \%$ compared with supplementary lighting with. 


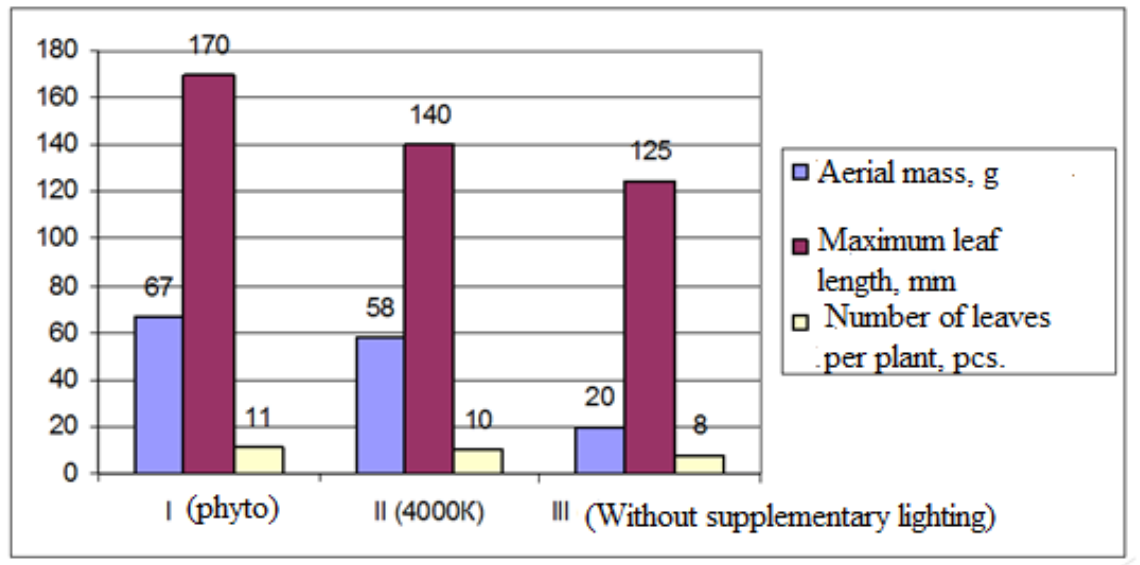

Figure 5. Results of the study of the influence of the spectral composition of LED radiation on the leaf lettuce irradiation efficiency under natural light. lighting.

General-purpose LED, and by 3-4 times compared with the variant without artificial

Study of the influence of the spectral composition of LED radiation on the efficiency of irradiation without natural light. The third series of laboratory experiments used three modes of exposure:

- phyto-LEDs irradiation for 14.5 hours (6.00 - 21.30);

- LEDs irradiation with $\mathrm{T}_{\mathrm{col}}=4000 \mathrm{~K}$ for 14.5 hours $(6.00-21.30)$;

- LEDs irradiation with $\mathrm{T}_{\mathrm{col}}=6500 \mathrm{~K}$ for 14.5 hours $(6.00-21.30)$.

The results of experimental studies are presented in Figure 6, that draw us to the conclusion that the use of phyto-LEDs for the artificial lighting of Moskovskii Parnikovyi lettuce can increase its productivity compared to general-purpose LEDs irradiation by more than $30 \%$. In this case, no significant difference in exposure between LEDs with $\mathrm{T}_{\mathrm{col}}=4000 \mathrm{~K}$ and $\mathrm{T}_{\mathrm{col}}=$ $6500 \mathrm{~K}$ was detected.

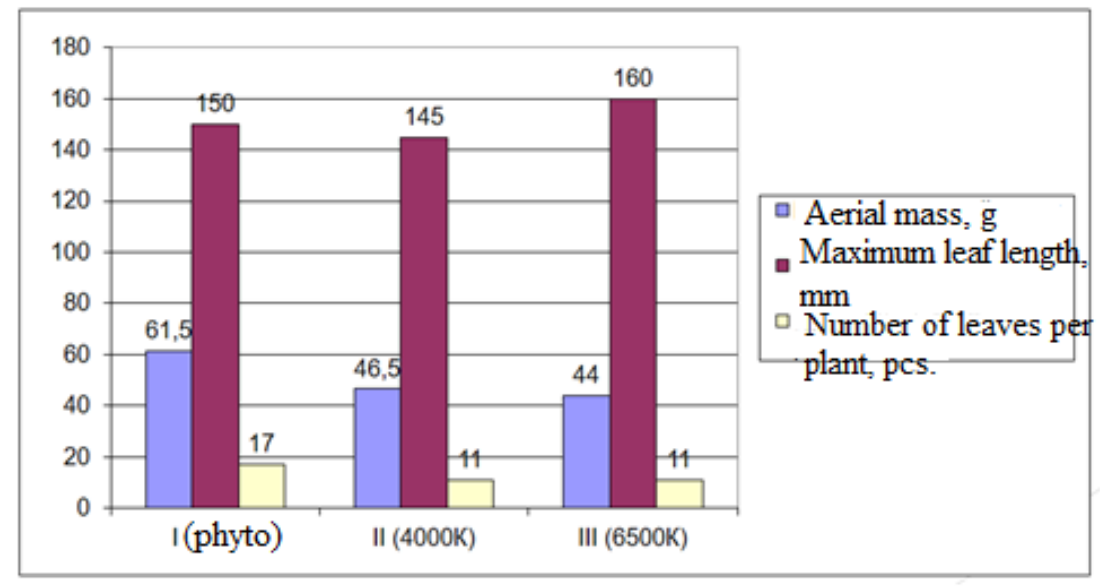

Figure 6. Results of the study of the influence of the spectral composition of LED radiation on the leaf lettuce irradiation efficiency without natural light.

Study of the effect of the periodic exposure on its effectiveness in the absence of natural light. The fourth series of laboratory experiments used three modes of exposure: 
- continuous irradiation with one LED with $\mathrm{T}_{\mathrm{col}}=4000 \mathrm{~K}$ with a daylight duration of 15 hours (6.00 - 21.00);

- interval irradiation with one LED with $\mathrm{T}_{\text {col }}=4000 \mathrm{~K}$ (the interval is $2 \mathrm{~s}$, the luminescence duration is $1 \mathrm{~s}$, and the daylight duration is 15 hours $(6.00-21.00)$;

- interval irradiation with two LEDs with $\mathrm{T}_{\mathrm{col}}=4000 \mathrm{~K}$ (the interval is $2 \mathrm{~s}$, the luminescence duration is $1 \mathrm{~s}$, and the daylight duration is 15 hours $(6.00-21.00)$.

The results of experimental studies of intermittent irradiation modes (Figure 7) showed that with periodic irradiation of lettuce with a frequency of $0.5 \mathrm{~Hz}$, the irradiation efficiency of lettuce decreases. Continuous irradiation is more effective with equal irradiation power and much more effective than low-power interval irradiation.

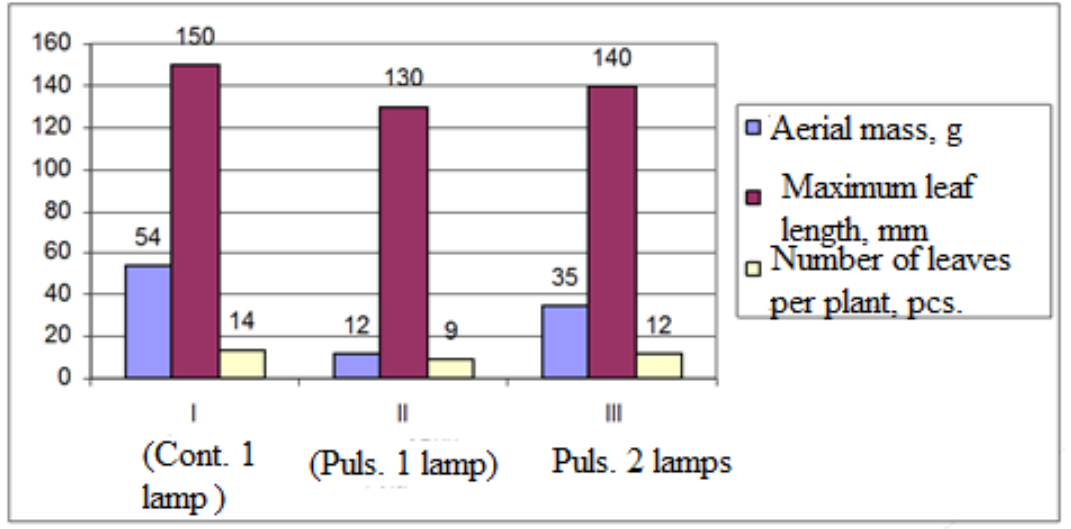

Figure 7. Results of the study of the influence of interval irradiation on the leaf lettuce irradiation efficiency without natural light.

\section{Results}

The results of comparative experimental studies have shown that LED irradiation favorably affects the growth and development of plants of the Moskovskii Parnikovyi variety. Supplementary lighting with LEDs allowed the plants to form a more developed system of leaves, stems, and roots. The use of pulsed radiation with long periods provides no positive effect. Lettuce plants irradiated with continuous radiation have an advantage in growth and development compared to plants irradiated with pulsed radiation.

Thus, phyto-LEDs are more effective for growth of Moskovskii Parnikovyi leaf lettuce in terms of its productivity compared with general-purpose LEDs with equal electric power consumption.

\section{References}

Brian, Z., Jiang, N., Grundy, S., \& Lu. C. (2018). Uncovering LED light effects on plant growth: new angles and perspectives - LED light for improving plant growth, nutrition and energy-use efficiency. Acta Horticulturae, 1227, 491- 498.

Bula, R. J., Morrow, R. C., Tibbitts, T. W., Barta, R. W., Ignatus, R. W., \& Martin, T. S. (1991). Light emitting diodes as a radiation source for plants. HortScience, 26, $203-205$.

Hoenece, M. D., Bula, R. J., \& Tibbitts, T. W. (1992). Importance of «blue» photon levels for lettuce seedlings grown under red light-emitting diodes. HortScience, 27, $427-430$. 
Kim, H. H., Goins, G. D., Wheeler, R. M., \& Sager, J. C. (2004). Green-light supplementation for enhanced lettuce growth under red- and blue-light-emitting diodes, HortScience, 39, $1617-1622$.

Kurshev, A. E., Bogatyrev, S. D., Zheleznikova, O. E., \& Sinitsyna, L. V. (2019). Highly efficient phytoradiator development for plant photoculture based on combined spectrum. International Journal of Innovative Technology and Exploring Engineering, 8(3), 392394.

Mokronosov, A. T., Gavrilenko, V. F., \& Zhigalova, T. V. (2006). Photosynthesis. Physiological, environmental, and biochemical aspects. M.: Publishing Center "Akademiia”, p. 356.

Pchelin, V. M., \& Makarova, I. E. (2018). Assessment of the status and development prospects of irradiation systems in modern greenhouse complexes. Lighting engineering, 1, 23 - 27.

Prikupets, L. B. (2017). Technological lighting in agroindustry of Russia. Lighting engineering, 6, 6-14.

Tewolde, F. T., Shiina, K., Maruo, T., Takagaki, M., Kozai, T., \& Yamori, W. (2018). Supplemental LED inter-lighting compensates for a shortage of light for plant growth and yield under the lack of sunshine. PLoS One, 13(11), e0206592

Ulianova, N. M., \& Myshonkov, A. B. (2017). A methodology for a comparative study of the effectiveness of light sources for photosynthetic plant irradiation. A Scientific View into the Future, 5, 34-39. 